\title{
Management of asthma and the audit spiral
}

\author{
Christine E Bucknall
}

Asthma managment is often suboptimal. The reasons for this are many and varied and were well summarised by the authors of the British Thoracic Association's inquiry into asthma deaths in two regions of England, which found preventable factors to have occured in $86 \%$ of deaths (box). The authors concluded that doctors, patients, and their relatives had often failed to realise the severity of the fatal attack. ${ }^{1}$ Retrospective study is, of course, likely to draw conclusions such as these but it emphasises the fact that good management of asthma is a team effort.

\section{Audit of asthma care}

The work we have done at Glasgow Royal Infirmary has looked mainly at the doctor input to that effort and more specifically the hospital input. The parts that the patient, family, and general practice play are probably more important as only very few asthmatic patients are ever admitted to hospital with acute asthma. Nevertheless, getting the hospital management of asthma right may have important spin offs in terms of patient education and understanding and also in terms of good liaison between hospital and general practice.

Our interest was stimulated by observing deficiencies in the care of asthmatic patients

Table 1 Patient characteristics, 1985-6 prospective audit

\begin{tabular}{|c|c|c|}
\hline & $\begin{array}{l}\text { Medical firms including } \\
\text { respiratory physician } \\
\qquad(n=64)\end{array}$ & $\begin{array}{l}\text { Medical firms with no } \\
\text { respiratory physician } \\
(n=86)\end{array}$ \\
\hline Average (SD) age (years) & $44(19)$ & $51(20)$ \\
\hline $\begin{array}{l}\text { Diagnostic category: } \\
\text { No }(\%) \text { with good history with/without } \\
\text { pulmonary function tests }\end{array}$ & 49(77) & $63(73)$ \\
\hline $\begin{array}{l}\text { No }(\%) \text { with previous positive steroid } \\
\text { trial }\end{array}$ & $7(11)$ & $11(13)$ \\
\hline No $(\%)$ with "doubtful" history & $8(12)$ & $12(14)$ \\
\hline No (\%) smokers & $20(31)$ & $24(28)$ \\
\hline $\begin{array}{l}\text { No (\%) taking steroids (any form) } \\
\text { before admission }\end{array}$ & $35(60)$ & $55(64)$ \\
\hline $\begin{array}{l}\text { Mean (SD) No of previous admissions } \\
\text { Mean (SD) No of exacerbations of } \\
\text { asthma in past year }\end{array}$ & $\begin{array}{l}3(8) \\
4(5)\end{array}$ & $\begin{array}{l}4(8) \\
4(4)\end{array}$ \\
\hline $\begin{array}{l}\text { Mean (SD) duration of exacerbation } \\
\text { before admission (days) }\end{array}$ & $5(5)$ & $4(5)$ \\
\hline Mean (SD) initial pulse rate (beats/min) & $109(18)$ & $111(21)$ \\
\hline
\end{tabular}

Table 2 Differences in hospital management, 1985-6. Figures are numbers (percentages) of patients

\begin{tabular}{lcc}
\hline & $\begin{array}{c}\text { Medical firms including } \\
\text { respiratory physician } \\
(n=64)\end{array}$ & $\begin{array}{c}\text { Medical firms with no } \\
\text { respiratory physician } \\
(n=86)\end{array}$ \\
\hline Given oral corticosteroids & $53(83)$ & $58(67)^{\star}$ \\
Peak flow rate measured & $47(73)$ & $36(42)^{\star \star}$ \\
Inhaler technique assessed & $46(72)$ & $45(52)^{\star}$ \\
Inhaled therapy increased on discharge & $35(55)$ & $24(28)^{\star \star}$ \\
Review planned within 2 weeks & $58(91)$ & $47(56)^{\star \star}$ \\
Reviewed within 2 weeks & $21(33)$ & $7(8)^{\star}$
\end{tabular}

${ }^{\star} p<0.05 ;{ }^{\star \star} p<0.005$.

Preventable factors in asthma deaths
Corticosteroids and bronchodilators
underprescribed
Inhaled steroids frequently not given
Patient cooperation satisfactory in $47 \%$

seen as part of our routine clinical practice. We have now looked at the management of patients admitted with acute asthma over three time periods, each lasting a year: 1983, $1985-6$, and 1989. The $1983^{2}$ and $1989^{3}$ surveys were retrospective, the $1985-6$ survey $^{4}$ was prospective and entailed a follow up interview with patients as well as the case note review which was common to each survey period.

The 1985-6 survey was of central importance. In it patients with acute asthma, or wheezing illness if they were also nonsmokers, were identified from day to day by contact with the admitting medical firms. They were contacted while in hospital, and if they agreed to participate they were given an appointment for about a fortnight after their discharge; on that occasion, in the patient's own home, a checklist of questions was completed in the course of a semistructured interview. The interview included details of past and current asthma history and also specific questions about symptoms of asthma since discharge. A further checklist was used to record details of asthma management in hospital from the patients' case notes. In all, 157 cases ( $81 \%$ of the total for that year) were followed up in this manner.

One of the ways in which the data could be analysed was to look at the management of patients admitted to two medical firms in the hospital which do not have a respiratory physician and compare them with two medical firms which do. ${ }^{5}$ This analysis depended on the fact that the two patient groups were similar in terms of age, previous asthma management and treatment, severity of the index attack, and certainty of diagnosis of asthma (table 1). It showed that despite this initial similarity the two groups were treated differently, with significantly more patients under the care of the medical teams with a respiratory physician being treated with oral corticosteroids, having their peak flow rate monitored (to provide an objective measurement of severity of asthma), and having their long term regular treatment (usually inhaled steroids) increased at the time of discharge from hospital. Also, significantly more of this group were followed up in the 
Table 3 Differences in outcome, 1985-6. Figures are numbers (percentages) of patients

\begin{tabular}{|c|c|c|}
\hline & $\begin{array}{l}\text { Medical firms including } \\
\text { respiratory physician }\end{array}$ & $\begin{array}{l}\text { Medical firms with no } \\
\text { respiratory physician }\end{array}$ \\
\hline $\begin{array}{l}\text { Two weeks after discharge: } \\
\text { Sleep disturbance } \\
\text { Morning chest tightness } \\
\text { Wheeze on one flight of stairs }\end{array}$ & $\begin{array}{l}15(23) \\
24(37) \\
22(34)\end{array}$ & $\begin{array}{l}35(42)^{\star} \\
47(55)^{\star} \\
51(58)^{\star \star}\end{array}$ \\
\hline $\begin{array}{l}\text { By end of survey: } \\
\text { Readmitted with acute asthma }\end{array}$ & $1(2)$ & $15(20)^{\star \star \star}$ \\
\hline
\end{tabular}

* $p<0.05 ; " * 0<0.005$ undertaken, using the same methods as for the previous (1983) retrospective survey. For comparison acute asthma cases from the prospective 1985-6 survey whose final discharge summary code was asthma were included in the analysis, and consisting of 85 out of 157 cases for $1985(53 \%) .^{3}$

The three patient groups were similar in terms of age and sex, length of hospital stay, and severity of the index attack. Many more in 1989 were already taking high dose inhaled corticosteroids at the time of admission to hospital, although in this retrospective survey no confirmation of compliance was possible. In terms of hospital management, significant improvements in care were seen in the most recent survey period, with more patients receiving oral corticosteroids (fig 1) having their peak flow measured initially and serially while in hospital (fig 2), and being discharged taking oral corticosteroids (fig 3 ). The only finding at variance with the general evidence of major improvements in care was the observation that significantly fewer patients had their inhaled corticosteroid dose increased
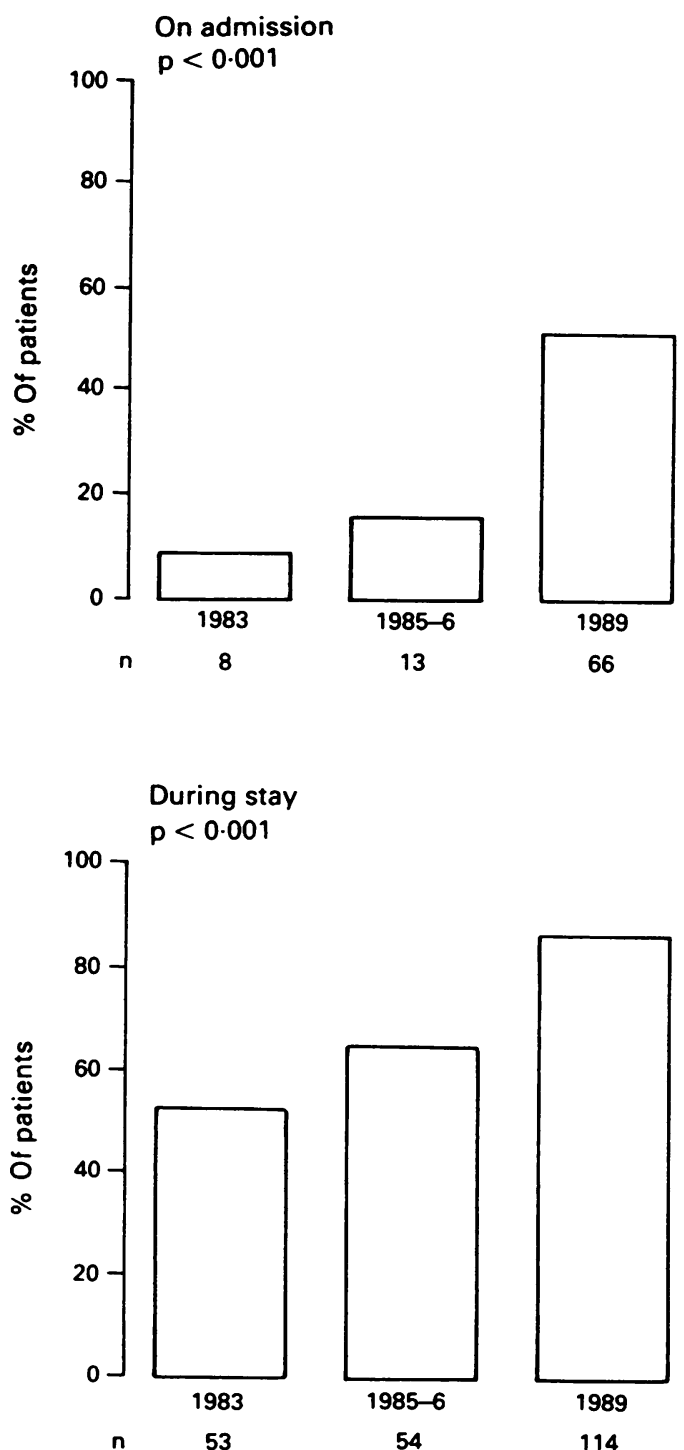

Fig 2 Recording of peak flow rate in patients with asthma 
Discharged taking oral CS $p<0.01$
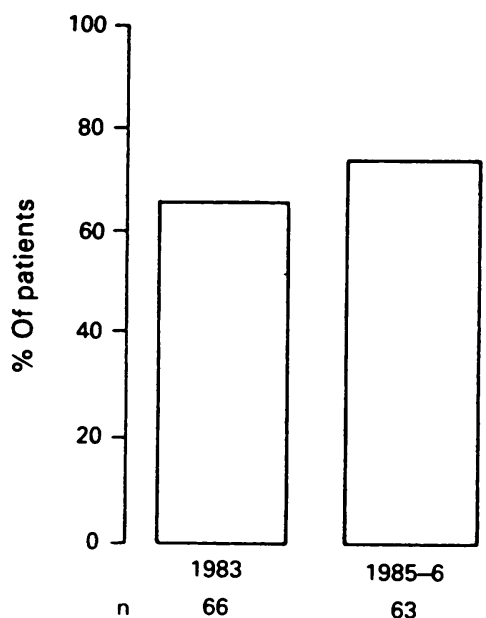

63

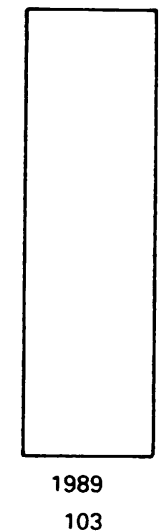

Inhaled CS increased on discharge $p<0.01$
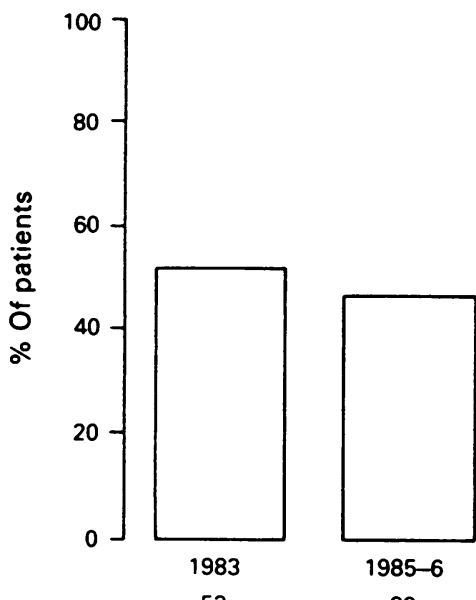

39

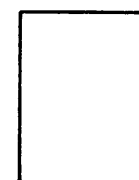

1989*

38

* Out of 119 patients lexcluding 14 patients transferred to adjacent chest unit for further treatment before discharge)

Fig 3 Steroid treatment after discharge (CS corticosteroids) ${ }^{3}$

at the time of discharge in 1989. However, this relates entirely to the fact that many more patients were already receiving high dose inhaled corticosteroids on admission so that further increasing the dose was difficult. ${ }^{3}$ Further assessment of the validity of this

observation entails looking at outcome and this is under way. This finding does, however, highlight the importance of adequate assessment of audit results obtained, which in turn requires careful thought at the start of an audit project to ensure that enough data are collected to be able to interpret the findings meaningfully.

\section{Improved management}

These findings are encouraging; the management of asthma in our hospital has significantly improved over the decade. It is, of course, fascinating to speculate on the reasons for this; we can discount any effect which the very valuable British Thoracic Society guidelines $^{67}$ have had, as the changes described here occurred before their publication. Possible underlying reasons for this improvement in care include:

- The audit process and feedback of results

- The association of management details with outcome measures

- The use of opinion leaders - the respiratory physicians in the hospital ${ }^{8}$

- An underlying, more widespread improvement in asthma care which we have simply observed.

This last possibility is not sufficient to account for the improvement, ${ }^{3}$ and teasing out the other possible factors may well be impossible. However, good medical audit is likely to have elements of all these other factors, when groups of doctors take time to appraise critically part of their practice where they identify a problem.

1 British Thoracic Association. Death from asthma in two regions of England. $B M 7$ 1982;285:1251-5.

2 Bucknall CE, Moran F, Stevenson RD. A retrospective survey of asthma management in hospital. Scot Med $\mathcal{J}$ 1988;33:328-30.

3 Bucknall CE, Robertson C, Moran F, Stevenson RD. Improving management of asthma: closing the loop or progressing along the audit spiral? Quality in Health Care progressing along

4 Bucknall CE, Robertson C, Moran F, Stevenson RD. Management of asthma in hospital: a prospective audit. Management of asthma

BMf 1988;296:1637-9.
Bucknall CE, Robertson C, Moran F, Stevenson RD. Differences in hospital asthma management. Lancet 1988;i:748-50.

6 British Thoracic Society. Guidelines for management of asthma in adults. I. Chronic persistent asthma. BMJ 1990;301:651-3.

7 British Thoracic Society. Guidelines for management of asthma in adults. II. Acure severe asthma $B M J$ 1990;301:797-800.

8 Lomas J, Enkin M, Anderson G, Hannah WJ, Vayda E Singer J. Opinion leaders vs audit and feedback implement practice guidelines. JAMA 1991;265:2202-7. 